\title{
Formação e aprendizagem docente: como os professores aprendem a ser professores?
}

\author{
Daliane do Nascimento dos Santos Rodrigues ${ }^{1}$
}

Maria do Socorro Lopes da Silva²

Kátia Regina Rodrigues Lima ${ }^{3}$

\section{Resumo}

Neste estudo busca-se analisar que concepções de aprendizagem docente se constituem na visão de professores em exercício. Para isso, realizou-se uma pesquisa de abordagem qualitativa com seis professores, que, através de suas narrativas, evidenciaram a experiência cotidiana como elemento determinante do aprendizado docente. Tal aprendizado é permeado pelo desejo de ser ou não professor, pelas angústias da trajetória docente e pela relação entre teoria e prática. Constatou-se que a reflexão sobre a aprendizagem docente é necessária, principalmente analisada pela perspectiva do professor. Os cursos de formação precisam conhecê-las e considerá-las para oportunizar um conhecimento significativo, que venha a contribuir com o trabalho docente.

Palavras-chave: Formação; Aprendizagem Docente; Ser Professor.

\section{Literacy environment in preschool from a world reading perspective: teachers in dialogue}

\begin{abstract}
This study intends to analyze which conceptions of teacher learning are constituted in the view of practicing teachers. For this, a qualitative research was carried out with six teachers, who, through their narratives, highlighted daily experience as a determining element of teacher learning. Such learning is permeated by the desire to be or not to be a teacher, by the anxieties of the teaching trajectory and by the relationship between theory and practice. It was found that reflection on teacher learning is necessary, mainly analyzed from the perspective of the teacher. Training courses need to know and consider them in order to provide meaningful knowledge, which will contribute to the teaching work.

Keywords: Formation; Teacher Learning; Being a Teacher.
\end{abstract}

\section{Introdução}

A formação docente se constitui em diferentes espaços potencializadores ao desenvolvimento profissional. Um desses espaços é constituído pela formação inicial, pois é nesse ambiente que o processo de aprofundamento dos estudos teóricos e reflexões acerca da complexidade que envolve a docência acontecem, sobretudo quando é refletido sobre o desempenho do professor e sua função social.

\footnotetext{
${ }^{1}$ Universidade Estadual do Ceará -UECE, Fortaleza, dalianenascimento@yahoo.com.br.

${ }^{2}$ Universidade Estadual do Ceará -UECE, Fortaleza, socorrolopes.mi@gmail.com.

${ }^{3}$ Universidade Estadual do Ceará -UECE, Fortaleza, katia.regina@uece.br.
} 
Segundo Serrazina (2012, p.267), "ser professor sempre foi uma profissão complexa. Esta complexidade tem tendência a acentuar-se com a incerteza e imprevisibilidade que caracteriza este início do século XXI". Logo, refletir sobre essa complexidade é fortalecer que a educação é compreendida como processo de formação humana e que o professor é parte constituinte desse desenvolvimento.

São notórias as mudanças substanciais ocorridas no contexto social e educacional, desde as leis que designam a formação inicial até o exercício desse profissional na educação básica. Nessa relação desafiante, o Ministério da Educação, em 2015, determinou novas Diretrizes Curriculares Nacionais para a formação inicial em Nível Superior (cursos de licenciatura, de formação pedagógica para graduados e de segunda licenciatura), por meio da Resolução $n$ ㅇ 2/CNE/2015, que menciona no primeiro parágrafo do Art. 2ㅇ a abrangência da docência:

Como ação educativa e como processo pedagógico intencional e metódico, envolvendo conhecimentos específicos, interdisciplinares e pedagógicos, conceitos, princípios e objetivos da formação que se desenvolvem na construção e apropriação dos valores éticos, linguísticos, estéticos e políticos do conhecimento inerentes à sólida formação científica e cultural do ensinar/aprender, à socialização e construção de conhecimentos e sua inovação, em diálogo constante entre diferentes visões de mundo (BRASIL, 2015).

Partindo da concepção de docência supracitada, ficam evidentes os desafios postos ao exercício da profissão docente, que requer uma formação sólida e compromisso social, o que implica em desafio, também, para os professores do ensino superior, responsáveis pela formação dos futuros professores que atuarão no contexto educacional.

Esse contexto social, cultural e educacional exige do professor múltiplas habilidades para lidar com diversas situações e relações sociais, o que requer um processo de formação contínua.

Reconhecer-se como um professor que tem um papel fundamental intrinsecamente ligado a esse processo de desenvolvimento formativo de forma contínua é respaldar-se para atuar nos distintos contextos com respeito e compromisso consigo mesmo e com os valores da diversidade e da diferença inerentes à educação escolar. Logo, o desenvolvimento profissional 
parte da formação inicial e continuada perpassando por todo o exercício docente, portanto "desse ponto de vista, desenvolvimento profissional docente pode ser entendido como uma atitude permanente de indagação, de formulação de questões e procura de soluções" (MARCELO, 2009, p.9).

Nesse âmbito de desenvolvimento profissional contínuo, brota uma perspectiva de renovação do exercício docente em uma profícua aprendizagem, da qual emana disciplina e envolvimento pleno com o que se faz. Mizukami (2004, p.38) acentua que "a base do conhecimento para o ensino consiste de um corpo de compreensões, conhecimento, habilidades e disposições que são necessários para que o professor possa proporcionar processos de ensinar e de aprender, em diferentes modalidades de ensino". Sendo assim, essa formação deve considerar inicialmente a aprendizagem do ofício de aluno e a observação cotidiana do trabalho docente (FORMOSINHO, 2009).

O docente, assim, se constitui em uma relação de integração e fortalecimento com o aprender e em vivenciá-la em diferentes condições e formas. Diante das reflexões introdutórias, este artigo objetiva analisar que concepções de aprendizagem docente se constituem na visão de professores em exercício. Para tanto, buscamos desenvolver nossa pesquisa em uma abordagem qualitativa. Na busca pela aproximação da realidade, utilizamos a narrativa como técnica para a coleta de dados.

É nesse cenário que se faz imperativa a discussão sobre esses desafios que constituem a profissão dos professores que estão em pleno exercício, refletindo acerca de como a aprendizagem docente acontece nesse processo.

Após a apresentação da introdução, delineamos, na segunda sessão, o caminho metodológico percorrido na realização da pesquisa. A terceira sessão, intitulada de $A$ formação do professor: dilemas, limites e possibilidades com as subseções: aprendizagem docente e ser docente, versa sobre as dificuldades e as expectativas no exercício da docência. Por conseguinte, na quarta sessão, discutimos os resultados das narrativas, compreendendo as percepções dos docentes. Por último, apresentamos as considerações finais, visto que as análises e os consequentes resultados advieram das categorias que a pesquisa admitiu. 


\section{Metodologia}

Metodologicamente, essa é uma pesquisa de abordagem qualitativa que pontua a forma singular dos sujeitos pesquisados. "Seu foco é, principalmente, a exploração do conjunto de opiniões e representações sociais sobre o tema que se pretende investigar" (GOMES, 2007, p.79).

Com relação à técnica de coleta de dados, utilizamos a narrativa como pergunta norteadora através da gravação de áudio, enviada por meio eletrônico em virtude da pandemia do COVID-19, em que foi necessário o isolamento social. Antes foi solicitada a permissão para proceder à gravação através da assinatura de um Termo de Consentimento Livre e Esclarecido (TCLE), assegurando a integridade de todos os participantes.

Para seleção dos participantes da pesquisa elegemos como critério de inclusão o professor em exercício na sala de aula e a sua formação para atuação nos seguintes níveis de ensino: Educação Básica (Educação Infantil, Ensino Fundamental e Médio) e Ensino Superior. Como nossa intenção é analisar que concepções de aprendizagem docente se constituem na visão de professores em exercício, julgamos o quantitativo de 02 professores por área de formação como amostragem suficiente para constituir os dados. Deste modo, foram selecionados: 02 Professores Pedagogos, 02 Professores de Disciplinas Específicas e 02 Professores Universitários.

Os 06 participantes da pesquisa serão identificados neste trabalho da seguinte forma: (PP1) Professor Pedagogo que atua Educação Infantil; (PP2) Professor Pedagogo que atua no Ensino Fundamental - Anos Iniciais; (PDE1) Professor de Disciplina Específica que atua no Ensino Fundamental - Anos Finais; (PDE2) Professor de Disciplina Específica que atua no Ensino Médio; (PU1) e (PU2) Professor Universitário que atua no Ensino Superior.

Para a análise de dados, adotamos os princípios da análise de conteúdo de Bardin (2011) e Franco (2012), que orientam a análise de dados a partir do estabelecimento de categorias. Neste estudo, elegemos como categorias: aprendizagem cotidiana; desejo de ser ou não professor; angústias da trajetória docente e a relação entre teoria e prática. 
Formação do professor: dilemas, limites e possibilidades

Atualmente o professor enfrenta sérias dificuldades, seja atuando no Ensino Superior na formação de professores ou na Educação Básica. Trata-se de uma profissão que exige conhecimento, habilidades, técnicas, reflexão, sensibilidade para agir de forma planejada. É necessário aprimorar-se para inovar suas práticas diante das incertezas, das situações inusitadas que envolvem o seu trabalho com o ensino e aprendizagem.

Para Charlot (2014), existe uma tensão no processo de ensino e aprendizagem, que é ocasionada quando não há aprendizagem do aluno. Para ele só aprendemos quando desenvolvemos uma atividade intelectual, o que não podemos fazer pelo outro. Desse modo, quando o aluno não quer aprender e não aprende, chegamos ao fracasso que é cobrado como responsável tanto o aluno quanto o professor. Nessa situação, "o aluno depende da professora, mas, também, esta depende dele. Sendo assim, permanentemente, o professor deve pressionar o aluno, negociar, procurar novas abordagens dos conteúdos ensinados, adaptar o nível da sua aula, sem por isso renunciar à transmissão do saber" (CHARLOT, 2014, p.50).

Gatti (2017, p.1153) acentua que “[...] é necessária uma formação para a comunicação efetiva professores-alunos, para a escuta efetiva alunos-professores, para o diálogo pedagógico visando à construção e constituição de aprendizagens". Estabelecendo esse movimento de constituição da docência que não se centra apenas na sala de aula, mas que perpassa o teórico e o prático articulando-os, trazendo-os sempre à luz da reflexão em busca da produção do conhecimento e de seu desenvolvimento através da formação em sua totalidade, esse processo produz um revide com um leque de possibilidades e experiências.

Nessa perspectiva: "a experiência provoca um efeito de retomada crítica (retroalimentação) dos saberes adquiridos antes ou fora da prática profissional. Ela filtra e seleciona os outros saberes, permitindo assim aos professores reverem seus saberes, julgá-los e avaliá-los" (TARDIF, 2014, p.53). Assim, o ambiente de trabalho do professor é um importante espaço de formação, pois proporciona a aprendizagem docente, seja entre os pares professores principiantes apoiados pelos demais; seja na própria sala de aula, diante as condições diárias com os discentes. É nesse esforço contínuo que o professor se articula e se reverbera, objetivando aperfeiçoar o seu trabalho numa perspectiva de mudanças que sejam significativas. 


\section{Aprendizagem docente}

Todas as experiências vivenciadas ao longo da formação inicial e/ou as construídas no exercício profissional constituem a aprendizagem docente. Esse processo se efetiva nos mais diversos âmbitos que abrangem o fazer docente. Neste sentido, vislumbrar os diferentes meios de aprendizagem docente permite considerar que se trata de uma postura ética e responsável nos desafios contidos na profissão, seja em caráter inicial de uma pretensa carreira, seja para aqueles que já se encontram firmes no exercício da docência.

Diante as considerações, Freire (2013) acentua que:

[...] a responsabilidade ética, política e profissional do ensinante lhe coloca o dever de se preparar, de se capacitar, de se formar antes mesmo de iniciar sua atividade docente. Esta atividade exige que sua preparação, sua capacitação, sua formação se tornem processos permanentes. Sua experiência docente, se bem percebida e bem vivida, vai deixando claro que ela requer formação permanente do ensinante. Formação que se funda na análise crítica de sua prática (p.56).

É neste construto pessoal, profissional e relacional de convivência com os demais que também acontece a partilha de experiências entre os pares, permitindo uma aprendizagem de forma contínua e processual. Na mesma concepção, Tardif $(2014$, p.52) afirma que "é através do confronto entre os saberes produzidos pela experiência coletiva dos professores que os saberes experienciais adquirem certa objetividade". Dessa forma, a valorização dos diferentes saberes em diferentes aspectos contribui na aproximação de intervenção na realidade, na práxis pedagógica, na quebra de paradigmas, na construção identitária em um processo de aprendizagem constante, que não se finda em si mesmo.

\section{Ser docente}

Considerar as aspirações ou mesmo determinadas circunstâncias que levam o indivíduo à escolha da profissão docente permite mostrar o caminho de uma carreira complexa que nos primeiros confrontos entre o que é aprendido na universidade e os contatos com a real situação de sala de aula, trata-se de algo que é decisivo no processo de aprendizagem do se fazer docente. 
As discussões sobre ser professor(a) na atualidade, demanda enfrentar os desafios imposto à carreira docente, as angústias quanto à realidade social, a falta de formação continuada, as questões salariais frente à questionável remuneração para o trabalho pedagógico, a busca de valorização social, o enfrentamento das novas tecnologias e sala de aula, entre outros (CORRÊA; BEHRENS, 2014, p.50).

Todas essas situações fazem parte do cotidiano docente e de certa forma influenciam na constituição da identidade desse "ser professor" que é afetado durante a sua carreira pelos desafios que são impostos. O estágio realizado na graduação é a primeira porta de acesso a esse confronto com a realidade da profissão, em que a teoria e a prática se fazem presentes, pois "o estágio, ao contrário do que se propugnava, não é atividade prática, mas teórica, instrumentalizadora da práxis docente, entendida esta como atividade de transformação da realidade" (PIMENTA; LIMA, 2010, p.45). O estágio sendo a primeira experiência docente que os graduandos vivenciam ainda em formação, se constitui um espaço para que a identidade docente passe a ser construída permeada por possibilidades e desafios.

Dessa forma, esse diálogo entre teoria e prática deve ser feito a partir de uma relação íntima e sólida como uma experiência potencializadora de aprendizagem, constituidora da profissão e reflexão com vistas à práxis docente. Com esse anseio, Therrien e Nóbrega-Therrien (2013) apontam que a reflexão crítica e transformadora da ação da docência de forma dialógica demanda dos participantes uma nova postura de entendimentos, convergindo com a produção de sentidos, a acepções de novos saberes que contribuam na construção de suas identidades de uma forma autônoma e socialmente emancipatória.

Para avançar em todos os aspectos mencionados, é importante reconhecer que o aperfeiçoamento permanente é necessário, quer para os profissionais em exercício e já formados, quer para os que ainda estão no processo de formação.

\section{Analisando dados: como o professor aprende a ser professor?}

Quando falamos sobre aprendizagem docente, logo associamos a ideia de aprendizagem aos saberes docentes, ou seja, saberes necessários para a prática docente, o que inclui saberes da formação docente, saberes pedagógicos, saberes disciplinares, saberes curriculares e saberes 
experienciais. Tardif (2014), que aponta esses saberes como conhecimentos que permeiam a ação docente, nos leva a refletir sobre o fato de que eles são resultados das aprendizagens dos professores durante o seu percurso formativo e trajetória profissional.

Ao pensarmos sobre aprendizagem docente na perspectiva do professor, especificamente, buscamos responder: Como você, professor, aprendeu a ser professor? O que está por trás das aprendizagens constituídas pelo professor? O que o influencia e o motiva a ser professor? A aprendizagem docente ocorre de forma igualitária para todo professor?

A partir da nossa coleta de dados, analisamos narrativas de seis professores (da Educação Básica e Ensino Superior), os quais possuem diferentes formações e públicos diferentes, entre os quais destacamos os pedagogos que trabalham com crianças, os professores de disciplina específica que trabalham com adolescentes e os professores universitários que trabalham com um grupo de jovens e adultos universitários. Conhecer o perfil desses professores é procurar reconhecer o seu lugar de fala, isto é, uma fala que parte de um formato de formação e atuação docente específica e determinante para que os professores, partindo de perspectivas diferentes, nos revelem como aprendem a ser professores.

Em nossas análises verificamos que os professores trazem uma fala recorrente no que diz respeito à aprendizagem, que se refere a experiência cotidiana na atuação como professor. Vejamos as falas:

[...] Aprendo a ser professor no fazer diário. Lembro-me que no início de minha profissão docente, me questionei se de fato era essa profissão que eu queria levar a frente, depois percebi que exatamente nessas reflexões é que eu estava me tornando uma professora. A cada ano que passa nos tornamos professores diferentes, ou seja, aprender a ser professor é um processo contínuo. Eu me torno professora a cada dia, com novas percepções, sensações, alegrias e as dores que minha profissão permite, me reconstruo e me dou a oportunidade de aprender a descobrir e assimilar a docência (PDE1).

[...] me realizo e aprendo todos os anos a cada turma e cada dia com os meus pequenos, pela forma que ensino ludicamente e pelos desafios encontrados (PP2).

Acredito que ninguém nasce professor/professora, é algo que se dá no processo. E assim, compreendo que nesse processo nunca estamos prontos, nos fazemos todos os dias, nos construímos em cada aula, em cada reflexão feita no coletivo, nos embates políticos e pedagógicos, nas experiências cotidianas com os alunos e os demais envolvidos no processo de ensinar e aprender. É no

Periódico Horizontes - USF - Itatiba, SP - Brasil - e021064 
processo construtivo-interpretativo de nosso fazer docente que vamos nos tornando e aprendendo a ser professor/professora. É um processo contínuo. Assim, é nesse contexto, por meio de minhas experiências individuais e sociais, nas relações individuais e sociais construídas e que vem sendo tecidas, sejam elas, experiências de formação, com meus alunos, com meus pares e com a realidade social, política do país que venho aprendendo a ser e a me tornar professor. Nesse sentido, me vejo sempre com um ser professor ainda em construção permanente (PU1).

Considerando a fala dos professores: "aprendo a ser professor no fazer diário", "aprendo todos os anos a cada turma e cada dia" e "nunca estamos prontos, nos fazemos todos os dias, nos construímos em cada aula", observamos o seu entendimento de que a aprendizagem é diária. Essa compreensão nos fez levantar a seguinte questão: o que acontece no cotidiano do trabalho do professor que promove a aprendizagem? Um dos professores responde: "em cada reflexão feita no coletivo, nos embates políticos e pedagógicos, nas experiências cotidianas com os alunos é demais os envolvidos no processo de ensinar e aprender" (PU1).

É no processo de reflexão cotidiana sobre a prática pedagógica que os professores aprendem. Isto é, a existência do professor reflexivo permite que, ao refletir sobre a sua prática criando novas formas de trabalho e tomando decisões que venham a promover o processo de ensino e aprendizagem dos alunos, o professor entenda que ele aprende a ser professor. Imbernón (2010) acentua que o docente tem a capacidade de desenvolver o conhecimento pedagógico por meio de sua prática, em seu trabalho diário com os alunos. $O$ autor reforça que "a ideia de professor reflexivo, que reflete em situação e constrói conhecimento a partir do pensamento sobre a sua prática, é perfeitamente transponível para a comunidade educativa que é a escola" (IMBERNÓN, 2010, p.47-48).

Entender que ser um professor reflexivo possibilita a aprendizagem docente é pensar na importância de formação inicial que possibilite formar professores reflexivos. Nessa perspectiva, Alarcão (2010) destaca que a capacidade de reflexão é inata ao ser humano, mas necessita de um contexto que possa mobilizar o seu desenvolvimento. Assim, tanto a formação inicial quanto a continuada devem favorecer e dedicar espaços para que os professores reflitam sobre diversas práticas de ensino, de modo que esse conhecimento repercuta na sua trajetória profissional.

Além dos relatos dos professores sobre sua aprendizagem através da experiência cotidiana na instituição de ensino, identificamos outros aspectos que estão nas entrelinhas da 
aprendizagem docente e que entendemos que também influenciam esse processo de aprendizagem: desejo de ser ou não professor; angústias da trajetória docente e a relação entre teoria e prática.

\section{O desejo de ser ou não professor}

Será que o desejo de ser ou não professor influencia na aprendizagem docente? Ele pode ser determinante para a ação pedagógica? Todo professor sentiu ou sente o desejo de atuar na profissão que escolheu? Quando o desejo de ser professor surge? Bem, quando pensamos na palavra "desejo", entendemos que fazer algo que desejamos nos dá prazer, promove satisfação, mas quando não desejamos, a relação não se estabelece de forma positiva; a falta de motivação e de interesse pode sim fragilizar uma ação. Para refletirmos sobre esses questionamentos e o interesse pela profissão docente, vejamos o que os professores falaram sobre o desejo e a aprendizagem docente:

O fato é que sempre desejei ser professora desde o início de minha vida estudantil por espelhar-me na minha primeira professora e por ter um pai muito rigoroso e comprometido com a educação dos filhos. Minha vida profissional foi e é de "idas e vindas" por acreditar no poder da educação. E, contudo, vivi várias experiências ora desafiadoras (que poderiam ter me levado a desistência), ora de sucessos que me faziam recriar forças para continuar. Mas vale lembrar que os bons acontecimentos sempre reinaram e sou feliz naquilo que realizo (PP1).

Desde criança já suscitava em mim, o desejo de ser professora em observar meus professores, dessa forma eu já estudava focada com a expectativa de ser professora. Meu primeiro contato foi em uma turma de Educação Infantil I, numa escola privada antes mesmo de ser graduada. Fui crescendo junto a escola, pois passei a lecionar nos Anos iniciais e Finais, só depois de minha experiência, ingressei na Faculdade de Pedagogia e em paralelo na rede municipal, quando fui lotada na Educação Infantil e permaneço até os dias atuais, me especializei em Educação Infantil, me realizo e aprendo todos os anos a cada turma e cada dia com os meus pequenos, pela forma que ensino ludicamente e pelos desafios encontrados(PP2).

Primeiramente gostaria de falar que não foi uma escolha, não foi uma opção minha, mas da minha mãe, por incrível que pareça. Aqui na cidade onde eu moro tem um campus da UERN e minha mãe quando eu prestei vestibular, disse que você precisa escolher esses cursos que tem aqui porque você não vai sair da cidade para estudar na capital, que era o meu sonho, desejo, ou na cidade

Periódico Horizontes - USF - Itatiba, SP - Brasil - e021064 
próxima que era Mossoró, ela não me deixou ir. Então eu tive que escolher entre os cursos que temos aqui e entre esses cursos eu escolhi Letras, que era o que eu me identificava mais. E eu lembro que eu ia assistir às aulas com muita raiva, assistir às aulas todas as noites, às vezes eu ia chorando, às vezes eu ia obrigada, mas terminei o curso, consegui terminar mesmo assim, porque durante o curso, já na metade do curso eu passei a produzir artigos, comecei a entrar no mundo da pesquisa e isso me fez gostar do curso de Letras e eu gostava pelo menos de assistir as aulas de produzir artigos, de apresentar trabalhos. Mas até aqui eu não tinha experiência de sala de aula e quando eu terminei, eu segui direto para o mestrado. Aí passei três anos para começar a lecionar, mas chegou uma oportunidade de dar aula em uma escola [...]. Aprendi a ouvi-los, aprendi a saber e a entender que eles têm limitações e que às vezes as nossas estratégias, nossos planos e a teoria que a gente estuda tem que ser totalmente modificada a partir de tudo isso que a gente vê, a partir da vivência com os nossos alunos, com a história de vida deles. E foi assim que eu aprendi, que eu me tornei professora, e hoje eu gosto da minha profissão [...] (PDE2).

Ao analisar as falas, observamos que as duas professoras pedagogas relatam que sempre desejaram ser professoras. Ao relatarem essa intenção, retomam suas memórias ao mencionar que o interesse partiu da experiência que tiveram com professoras durante a sua trajetória escolar. Agora, enquanto docentes, revelam os desafios da profissão, ressaltam as aprendizagens que conquistam a cada nova experiência em sala de aula, demonstrando que o desejo de ser professor antes mesmo de exercer a profissão se mantém firme.

Ao contrário das professoras que manifestam seu interesse antes mesmo de iniciarem a formação acadêmica, temos no relato da professora dos anos finais, uma experiência diferente. Ela menciona que ser professora não foi uma opção sua, destaca o quanto foi difícil durante a graduação seguir no curso sem essa relação de desejo. Porém, ao se envolver com as atividades de pesquisa que o curso de licenciatura oferecia, passou a construir uma relação mais prazerosa com a sua formação. O desejo pela profissão docente não foi inspirado antes da graduação como as demais professoras, mas sim através da atividade de pesquisa oferecida pelo curso.

Ter o desejo de ser professor e descobrir esse desejo a partir das experiências que se vive na formação e no próprio exercício da profissão nos mostra que, além do desejo, outros aspectos também influenciam a aprendizagem, entre os quais estão “interesse, compromisso, necessidade, curiosidade, disciplina, gosto pelo que faz, dimensionamento da tensão, preconceito, teimosia, emoções, vínculo, entusiasmo, alegria, euforia e determinação." (PLACCO; SOUZA, 2006, p.18). As experiências que se transformam em saberes fazem parte da 
trajetória de vida do professor, em que fatores históricos, sociais e culturais perpassam e influenciam na constituição desse ser professor (FINGER, 2014).

Diante esses fatores, na caminhada docente, emergem sentimentos de alegria, interesse, compromisso, assim também as angústias surgidas perante a complexidade da profissão. Assim, podemos dizer, que muitos desses aspectos são encontrados nas falas das professoras. O desejo pela profissão, seja ele inicial ou não, influencia na aprendizagem do professor.

\section{As angústias da trajetória docente}

Acabamos de falar sobre como o desejo influencia na aprendizagem do professor, mas e sobre as angústias? Elas que estão presentes na trajetória de qualquer profissão. Podem elas ser um ponto de partida para aprendizagem docente? Vamos ver os que os professores dizem:

Ao final do curso me sentia inexperiente para atuar como professor, realidade que me levou a optar por trabalhar em empresas privadas. Até 2009 , ainda trabalhei nessa área quando fui motivado por um amigo a tentar uma experiência como professor. Prestei concurso para professor substituto na rede pública de educação de São Paulo e com a aprovação saí da área em que trabalhava, uma empresa de cosméticos. Fiquei dois anos no exercício da docência, dando aulas de Filosofia e Sociologia. Entretanto, encontrei uma série de dificuldades para me adaptar às dificuldades dos alunos, e despertar uma metodologia que facilitasse o aprendizado em sala e minha comunicação com a turma. No ano de 2003 retornei para minha terra natal, o Assú/RN, e comecei a ficar atento aos concursos na área de docência no ensino superior. Ainda estava um pouco frustrado com a experiência na educação básica, mas não queria desistir totalmente da área da educação. Sentia que poderia me encontrar com outro público. Apareceu uma vaga para professor substituto na Universidade Federal Rural do Semi-Árido (UFERSA - Angicos). Fiquei assustado de início, mas me inscrevi no processo e fui selecionado. A experiência no ensino superior modificou totalmente a forma como me entendia no campo da docência. Percebi que faltava amadurecimento intelectual e uma relação mais ampla com os conteúdos propostos. Dessa forma, me dediquei cada vez mais aos estudos identificando as possíveis dificuldades de aprendizagem dos alunos e ampliando as metodologias e processos de comunicação em sala (PU2).

[...] lembro que foi nos primeiros momentos, nas primeiras aulas eu tinha medo de não conseguir da conta, e não ter domínio em uma sala de aula, tinha medo dos alunos não me respeitarem, medo de não conseguir meus objetivos e aí durante essa vivência nesse dia a dia, como falei que a gente vai entendendo os alunos, vai entendendo qual é a dinâmica e hoje eu tenho um lema, para 
comigo como professora que, para sermos professores bons e para sermos professores precisamos ouvir a história dos alunos e foi aí que eu comecei a me apaixonar pela profissão e eu vi que eu podia fazer alguma coisa por eles. Nós não temos apenas a missão de ensinar gramática, ensinar leitura, ensinar a produzir um texto, mas ensinar esses alunos, coisas para a vida e eu vi que isso era uma oportunidade que eu tinha (PDE2).

Vimos que os professores falaram de medo e da frustração que sentiram, sensações que surgem quando ainda não nos sentimos seguros ou quando não se conquista inicialmente o resultado esperado. Ao passo que os professores apontam as sensações negativas que surgiram durante as experiências de trabalho, relatam que aprenderam através delas. Isso é observável em suas falas:

Percebi que faltava amadurecimento intelectual e uma relação mais ampla com os conteúdos propostos. Dessa forma, me dediquei cada vez mais aos estudos identificando as possíveis dificuldades de aprendizagem dos alunos e ampliando as metodologias e processos de comunicação em sala (PU2).

Para sermos professores precisamos ouvir a história dos alunos e foi aí que eu comecei a me apaixonar pela profissão e eu vi que eu podia fazer alguma coisa por eles (PDE2).

A percepção de que se pode aprender a partir de sensações e emoções negativas diante de uma situação vai ao encontro do que Marchesi (2008, p.106) fala ao discutir sobre as emoções dos professores. O autor destaca que a emoção envolve "percepção de uma situação em função dos objetivos pessoais e a disposição para determinadas ações. As emoções são, também, sinais de alerta que devem ser atendidos e orientações diante de determinadas situações que devem ser avaliadas". É o que percebemos nas falas dos professores, o medo e a frustração não permitiram que desistissem da profissão, mas que buscassem alternativas de trabalho.

Nóvoa (2007, p.16), ao refletir sobre como cada um se tornou o professor que é hoje, menciona três "A" que sustentam esse processo identitário: adesão, ação e autoconsciência.

- A de Adesão, porque ser professor implica sempre a adesão a princípios e a valores, a adoção de projectos, um investimento positivo nas potencialidades das crianças e dos jovens. - $A$ de Ação, porque também aqui, na escolha das melhores maneiras de agir, se jogam decisões do foro profissional e do foro pessoal. Todos sabemos que certas técnicas e métodos 'colam' melhor com a 
nossa maneira de ser do que outros. Todos sabemos que o sucesso ou insucesso de certas experiências 'marcam' a nossa postura pedagógica, fazendo-nos sentir bem ou mal com esta ou com aquela maneira de trabalhar na sala de aula. - $A$ de Autoconsciência, porque em última análise tudo se decide no processo de reflexão que o professor leva a cabo sobre a sua própria acção. É uma dimensão decisiva da profissão docente, na medida em que a mudança e a inovação pedagógica estão intimamente dependentes deste pensamento reflexivo.

Podemos encontrar no relato dos professores esses três aspectos: a adesão, quando não desistem do trabalho docente diante de uma dificuldade; ação, porque decidem como agir diante das situações que surgem; e autoconsciência, pois fazem uma reflexão sobre as suas ações e se percebem como professores. "Percebi que faltava amadurecimento intelectual e uma relação mais ampla com os conteúdos propostos". Ter essa compreensão parte de um exercício de autoconsciência que demanda reflexão do sujeito.

\section{Relação entre teoria e prática}

Quando ouvimos falar sobre a relação entre teoria e prática, um discurso nos vem à memória: teoria é uma coisa, prática é outra. De fato, são coisas diferentes, mas o que queremos destacar é o que está por trás desse discurso: a teoria não nos ajuda com a prática. Esse pensamento, presente em tantos discursos de professores e estudantes de graduação, nos chama a atenção. Encontramos, em uma fala docente, a relevância dessa relação para a sua aprendizagem. Vamos ver o que dizem os professores:

Em termos práticos, eu diria que nós aprendemos a ser professores estudando, planejando, tentando colocar em prática tudo aquilo que a gente vê na universidade, mas aprende a ser professor na sala de aula, a gente aprende a ser professor no dia a dia e foi assim que eu aprendi. [...] Aprendi a ouvi-los, aprendi a saber e a entender que eles têm limitações e que às vezes as nossas estratégias nossos planos e a teoria que a gente estuda tem que ser totalmente modificada a partir de tudo isso que a gente vê, a partir da vivência com os nossos alunos, com a história de vida deles e foi assim que eu aprendi, que eu me tornei professora, e hoje eu gosto da minha profissão, tanto eu gosto do mundo da pesquisa [...] (PDE2).

Depois da experiência na UFERSA, passei num processo para professor substituto no curso de Pedagogia da Universidade Estadual do Rio Grande do Norte (UERN - Mossoró). Nesse novo desafio me encantei com as possibilidades 
de atuação na área da Pedagogia, procurando aproveitar ao máximo as diversas concepções metodológicas e teóricas que o curso possibilita por meio de conteúdos interdisciplinares. Essa nova realidade fez com que observasse com mais atenção minha própria prática pedagógica, ampliando ainda mais os conhecimentos e procurando estar cada vez mais preparado para construir formas de aprendizagem em sala, considerando as relações cognitivas, afetivas e éticas que se estabelecem entre professor e alunos (PU2).

Observamos nas falas dos professores que um dos fatores que contribuem para a aprendizagem docente são os estudos teóricos realizados durante as formações. Ao mencionar "nós aprendemos a ser professores estudando, planejando, tentando colocar em prática tudo aquilo que a gente vê na universidade" (PDE2), a professora valoriza e mostra o quanto os estudos teóricos fizeram sentido para o seu trabalho enquanto docente. Observamos também a importância dos estudos e seus resultados positivos na seguinte fala:

Essa nova realidade fez com que observasse com mais atenção minha própria
prática pedagógica, ampliando ainda mais os conhecimentos e procurando
estar cada vez mais preparado para construir formas de aprendizagem em sala,
considerando as relações cognitivas, afetivas e éticas que se estabelecem entre
professor e alunos (PU2).

Identificar nas falas dos professores a importância dessa interdependência da teoria e prática, uma vez que "na sociedade moderna, o apelo à aplicação imediata da teoria sufoca o potencial crítico do pensamento e submete a própria teoria à impaciência da prática" (CONTE, 2016, p.887), nos faz perceber que a formação docente vem conseguindo avançar de um patamar em que a relação entre teoria e prática era vista de forma dissociada, resultado de uma epistemologia cartesiana, para uma compreensão de que teoria e prática não se dissociam na ação didática-pedagógica.

Temos aí presente na fala dos professores uma relação entre teoria e prática, que, de fato, se estabelece e que permite ao professor construir conhecimento. De acordo com Lima (2008, p.143), “a profissão docente vai sendo construída à medida que o professor articula o conhecimento teórico-acadêmico à cultura escolar e a reflexão sobre a sua prática", o que pode ser visto nas falas dos professores. Esse entendimento reforça o pensamento de Lima (2008), ao destacar que as formações direcionadas para professores, inicial e continuada, devem redirecionar as relações entre teoria e prática docente. É preciso oportunizar momentos em que 
os professores, nos seus cursos de formação, percebam como os estudos teóricos podem subsidiar a sua prática de modo que ele possa produzir conhecimento pedagógico.

\section{Considerações finais}

Neste estudo realizamos uma investigação buscando compreender como os professores aprendem a ser professores. Para isso, coletamos informações de docentes da Educação Infantil, Ensino Fundamental (anos iniciais e finais), Ensino Médio e Superior. A ideia era perceber a perspectiva de professores com formações diferentes e que atuam em diferentes níveis de ensino.

Os resultados apontaram que as aprendizagens docentes ocorrem através do cotidiano da sala de aula em um processo contínuo de ação-reflexão. Observamos também que esse processo contínuo de aprendizado é permeado pelo desejo de ser professor, pelas angústias da atuação docente e pela relação entre teoria e prática, tão debatida no espaço acadêmico.

Entre os aspectos de destaque discutidos estão o desejo como um mecanismo que os motiva e provoca interesse pela profissão, as angústias como uma sensação que os mobiliza a pensar em alternativas de trabalho, e não como motivo de desistência da profissão, e a relação teoria-prática, com destaque para os estudos teóricos, valorizados e citados como uma forma de obter bons resultados na prática pedagógica e no bom desempenho dos alunos.

Salientamos que este estudo alerta para a importância de ouvirmos mais o que os professores pensam sobre o seu próprio processo de aprendizagem, trazendo essa reflexão para o debate não só na formação inicial, mas principalmente na formação continuada, tendo em vista que muitos revelaram que aprendem a ser professores no cotidiano.

Para concluir, ressaltamos que falar sobre aprendizagem docente pode soar repetitivo. No entanto, entendemos que essa reflexão se faz necessária, uma vez que os professores de gerações diferentes não são os mesmos, assim como não são as necessidades de formação e atuação. Sempre irá surgir uma nova situação que demanda a aprendizagem do professor. Saber reconhecê-las é fundamental para que os cursos de formação possam se preparar e garantir aos futuros professores, e aos que já estão atuando, um conjunto de saberes e conhecimentos que possibilitem a articulação teoria-prática; uma atuação ancorada no contexto sociocultural e 
experiencial, rica em interações sociais e profissionais. Nessa perspectiva, a reflexão sobre a aprendizagem docente e o exercício de metapensamento são imprescindíveis no processo de construção do ser professor.

\section{Referências}

ALARCÃO, I. Professores reflexivos em uma escola reflexiva. 7. ed. São Paulo: Cortez, 2010.

BARDIN, L. Análise de conteúdo. Trad. Luís A. Reto e Augusto Pinheiro. São Paulo: Edições 70, 2011.

BRASIL Ministério da Educação. Conselho Nacional de Educação. Conselho Pleno. Resolução no $02 / C P / C N E / 2015$. Define as Diretrizes Curriculares Nacionais para a formação inicial em nível superior (cursos de licenciatura, cursos de formação pedagógica para graduados e cursos de segunda licenciatura) e para a formação continuada. Brasília: CP/CNE/MEC, 2015.

CHARLOT, B. Da relação com o saber às práticas educativas. São Paulo: Cortez, 2014.

CONTE, E. Notas sobre teoria e práxis. Educação e Filosofia, v.30, n.60, p.883-903, nov.2016.

CORRÊA, B. R. P.G.; BEHTRENS, M. A. Ser professor: teoria e prática numa nova visão paradigmática. In: FERREIRA, J. L (org.). Formação de professores: teoria e prática pedagógica. Petrópolis, RJ: Vozes, 2014. p.50-72.

FINGER, M. As implicações socioepistemológicas do método biográfico. In: NÓVOA, A.; FINGER, M. (orgs.). O método (auto)biográfico e a formação. Trad. Maria Nóvoa. 2. ed. Natal: EDUFRN, 2014. p.111-119.

FORMOSINHO, J. (coord.). Formação de professores: aprendizagem e acção docente. Porto: Porto Editora, 2009.

FRANCO, M. L. P. B. Análise de conteúdo. Brasília: Liber Livro, 2012.

FREIRE, P. Professora, sim, tia não: cartas a quem ousa ensinar. 24. ed., Rio de Janeiro: Paz e Terra, 2013.

GATTI, B. A. Didática e formação de professores: provocações. Cadernos de Pesquisa. v.47, n.166, p.1150-1164, out./dez. 2017. Disponível em:

https://www.scielo.br/j/cp/a/h9mXZyNRkNkb5Sy9KrjTrwz/?format=pdf\&lang=pt. Acesso em: 18 de agosto de 2021.

GOMES, Romeu. A análise de dados em pesquisa qualitativa In: DESLANDES, S. F.; GOMES, R.; 
MINAYO, M. C. S. (orgs.). Pesquisa social: teoria, método e criatividade. 33. ed. Petrópolis: Vozes, 2007, p. 79-108

IMBERNÓN, F. Formação docente e profissional: formar-se para a mudança e a incerteza. 9. ed., São Paulo: Cortez, 2010.

LIMA, A. C. R. E. Caminhos da aprendizagem da docência: os dilemas profissionais dos professores iniciantes In: VEIGA, I. P. A.; D'ÁVILA, C. M. (orgs.). Profissão docente: novos sentidos, novas perspectivas. 2. ed. Campinas: Papirus, 2008, p.135-150.

MARCELO, C. Desenvolvimento profissional docente: passado e futuro. Sísisfo- Revista de Ciências da Educação. n. 8, p.7-22, jan/abr. 2009.

MARCHESI, A. O bem-estar dos professores: competências, emoções e valores. Trad. Naila T. Freitas. Porto Alegre: Artmed, 2008.

MIZUKAMI, M. G. N. Aprendizagem da docência: algumas contribuições de Lee. S. Shulman. Educação. Santa Maria, v.29, n.2, 2004, p.33-49.

NÓVOA, A. Os professores e as histórias da sua vida In: NÓVOA, A. (org.). Vidas de professores. 2. ed. Portugal: Porto Editora, 2007, p.11-30.

PIMENTA, S. G.; LIMA; M. S. L. Estágio e docência. 5. ed. São Paulo: Cortez, 2010. (Coleção Docência em Formação / Série Saberes Pedagógicos).

PLACCO, V. M. N. S.; SOUZA, V. L. T. Grupo e autoria: aprendizagem do adulto professor. In: PLACCO, V. M. N. S.; SOUZA, V. L. T. (orgs.). A aprendizagem do adulto professor. São Paulo: Edições Loyola, 2006, p.11-24.

SERRAZINA, M. L. M. Conhecimento matemático para ensinar: papel da planificação e da reflexão na formação de professores. Revista Eletrônica de Educação, v.6, n.1, 266-283, maio 2012.

TARDIF, M. Saberes docentes e formação profissional. Petrópolis: Vozes, 2014.

TERRIEN.J; NÓBREGA-THERRIEN, S. M. A integração das práticas de pesquisa e de ensino e a formação do profissional reflexivo. Revista Educação, Santa Maria, v.38, n.3, p.619-630, set./dez. 2013.

Recebido em junho 2021.

Aprovado em novembro 2021. 